\title{
Safety and efficacy of enhanced recovery after surgery in elderly patients after therapeutic endoscopic retrograde cholangiopancreatography
}

\author{
Fang Niu ${ }^{1}$, Yu-Di Liü, Rong-Xia Chen ${ }^{1}$, Yu-Jun $\mathrm{Niu}^{3}$ \\ ${ }^{1}$ Department of Surgery, the First Affiliated Hospital of Jinzhou Medical University, Jinzhou, Liaoning, China \\ 2Department of Surgery, the First People's Hospital of Zunyi, Zunyi, Guizhou, China \\ ${ }^{3}$ Department of Radiology, the First Affiliated Hospital of Jinzhou Medical University, Jinzhou, Liaoning, China
}

Videosurgery Miniinv 2019; 14 (3): 394-400

DOI: https://doi.org/10.5114/wiitm.2019.82871

\begin{abstract}
Introduction: The number of elderly patients with biliary and pancreatic diseases has increased significantly. The characteristics of biliary and pancreatic diseases in the elderly increase the risk of treatment.

Aim: To study the safety and efficacy of therapeutic endoscopic retrograde cholangiopancreatography (ERCP) in elderly patients with biliary and pancreatic diseases with the concept of enhanced recovery after surgery (ERAS).

Material and methods: Patients receiving ERCP under ERAS were grouped into an elderly group (group A, $n=58$, aged 75 years or above) and a young and middle-aged group (group $B, n=202$, aged less than 60 years). The clinical parameters before, during and after the operation of the two groups were compared.

Results: Before the operation, the incidences of cholangiocarcinoma and complications, nutritional screening score $\geq 3$, ASA degree III and Child-Pugh grade A in group A were significantly higher than those in group $B(p<0.05)$, while the incidences of nausea and vomiting, abdominal pain, nutritional screening $<3$ and ASA grade I in group $A$ were significantly lower than those in group $B(p<0.05)$. Intraoperatively, the incidence of juxta-ampullary duodenal diverticulum (JAD) in internal or bottom papilla in the elder patients with difficult selective biliary cannulation (DSBC) was significantly higher than that in the young and middle-aged group $(p<0.05)$. In addition, the continuous ECG monitoring duration and the first exhaust time in group $A$ were significantly longer than those in group $B(p<0.05)$. Conclusions: Endoscopic retrograde cholangiopancreatography under ERAS in elderly patients is as safe and effective as in young patients.
\end{abstract}

Key words: enhanced recovery after surgery, endoscopic retrograde cholangiopancreatography, the elderly, biliary and pancreatic diseases.

\section{Introduction}

China has entered an era of aging of the population. The number of elderly patients with biliary and pancreatic diseases has increased significantly. Due to the gradual decline in the physical functional reserve, as well as more complications and high risk in operation and anesthesia, the complications of the operation and mortality of biliary and pancreatic diseases increase with age. The characteristics of biliary and pancreatic diseases in the elderly increase the risk of treatment. On one hand, the elderly are not sensitive to some general symptoms, which can easily delay the diagnosis and treatment. On the other hand, after a definite diagnosis, the patients often 
undergo conservative treatment due to the high risk of the operation, which can lead to missing the best opportunity for treatment. When the operation becomes unavoidable, the basic condition of the patients may be even worse. At this point, relieving the life-threatening symptoms and improving the quality of life of patients is an urgent priority [1, 2]. In recent years, research and clinical practice have proved that mechanical lithotripsy, stone removal and stent placement for benign and malignant stricture under endoscopic retrograde cholangiopancreatography (ERCP) can achieve the same therapeutic effect as the traditional surgical operation $[3,4]$.

In the concept of enhanced recovery after surgery (ERAS), first proposed by Professor Kehlet [5], according to the pathophysiological characteristics of the patients in the perioperative period, all kinds of methods proven to be effective by evidence-based medicine are used to minimize the stress response and organ dysfunction of the patients, so as to reduce complications and accelerate the postoperative rehabilitation. So far, ERAS has been used for nearly 20 years in clinical practice, especially in many surgical fields, and achieved good clinical results [6-9]. In January 2016, Chinese experts made the first Expert Consensus on ERAS for Hepatobiliary and Pancreatic Surgery (2015 Edition) [10]. In our hospital, ERCP treatment under ERAS has been carried out for more than 2 years, and achieved good clinical results and a large number of clinical experiences. However, there are few clinical reports on therapeutic ERCP under the concept of ERAS at home and abroad, especially on the safety and efficacy of ERCP treatment under ERAS in elderly patients.

\section{Aim}

In this study, we compared senile patients and young patients who suffered from biliary and pancreatic diseases and received therapeutic ERCP under ERAS, and retrospectively analyzed the safety and efficacy of therapeutic ERCP under ERAS in elderly patients with biliary and pancreatic diseases, so as to provide evidence for better clinical application and development.

\section{Material and methods}

\section{Subjects}

Patients hospitalized and receiving ERCP treatment in the Department of Hepatobiliary Surgery of the First Affiliated Hospital of Jinzhou Medical
University from April 2017 to December 2017 were enrolled in this study. Inclusion criteria were as follows: diagnosed as biliary and pancreatic diseases, receiving ERCP; American Society of Anesthesiologists (ASA) grade I-III. Exclusion criteria included: emergency operation; combined with severe cardiovascular disease, diabetes mellitus, serious infection; related drug allergy history and taboo; pregnant women, lactating mothers, etc. According to the new age stratification made by the WHO of the UN, the patients were divided into 2 groups: an elderly group (group $A, n=58$, aged 75 years or more) and young and middle-aged group (group $B$, $n=202$, aged less than 60 years). This study was conducted in accordance with the Declaration of Helsinki. This study was conducted with approval from the Ethics Committee of Jinzhou Medical University. Written informed consent was obtained from all participants.

\section{Observation index of ERCP and diagnosis and treatment}

The ERAS related indicators of the 2 groups were observed and collected preoperatively, intraoperatively and postoperatively. The difficulty of the operation was divided into 5 grades according to the Difficulty Classification (DC) made by Cotton et al. [11]; the postoperative pain was divided into mild, moderate and severe grades following the Visual Analogue Scale/Score (VAS); and the complications were classified according to the standard established by Cotton et al. [11] (Tables I-III). The ERCP operation was performed by the same surgeon with experience of more than 10 years. Postoperative vital signs and complications were monitored and treated immediately if necessary. The discharge standards included: the patient can basically self-care, the body temperature is normal; no fluid replacement is needed, normal diet; good organ function; pain is relieved or can be well controlled by oral analgesics; able to eat normally, unobstructed exhaust and defecation, wound healing well without infection. All patients signed written informed consent.

\section{ERCP procedure}

The patient received intravenous general anesthesia in a prone or semiprone position. Most of the cases of choledocholithiasis were confirmed by electronic duodenoscopy (TJF-260V, Olympus, Japan). The 
Table I. Comparisons of preoperative clinical parameters between the two groups

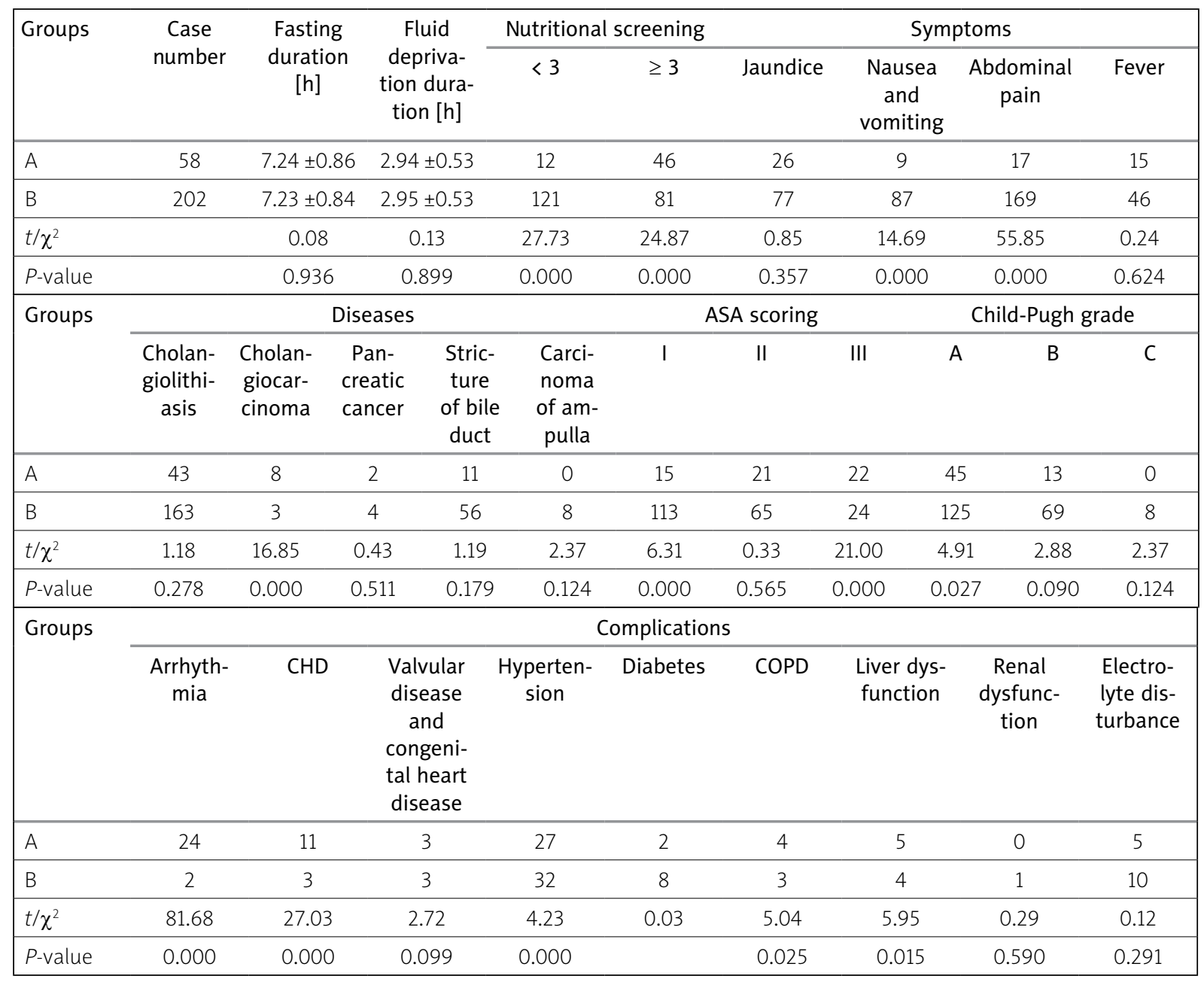

Table II. Comparisons of intraoperative clinical parameters between the two groups

\begin{tabular}{|c|c|c|c|c|c|c|c|c|}
\hline \multirow[t]{2}{*}{ Groups } & \multicolumn{8}{|c|}{ DSBC } \\
\hline & $\begin{array}{l}\text { Papillary } \\
\text { spasm }\end{array}$ & $\begin{array}{l}\text { Papillary } \\
\text { stenosis }\end{array}$ & $\begin{array}{l}\text { Intestinal } \\
\text { mucosa } \\
\text { edema }\end{array}$ & $\begin{array}{l}\text { Papillary } \\
\text { lateral } \\
\text { opening }\end{array}$ & $\begin{array}{l}\text { JAD in the } \\
\text { internal } \\
\text { or bottom } \\
\text { papilla }\end{array}$ & \multicolumn{3}{|c|}{ Billroth II or Roux-en-Y stomach jejunostomy } \\
\hline A & 0 & 10 & 56 & 1 & 27 & \multicolumn{3}{|c|}{0} \\
\hline$B$ & 0 & 39 & 193 & 7 & 17 & \multicolumn{3}{|c|}{1} \\
\hline$t / \chi^{2}$ & & 0.13 & 0.11 & 0.46 & 46.61 & \multicolumn{3}{|c|}{0.29} \\
\hline$P$-value & & 0.732 & 0.137 & 0.499 & 0.000 & \multicolumn{3}{|c|}{0.591} \\
\hline \multirow[t]{2}{*}{ Groups } & \multicolumn{5}{|c|}{ Grade of operation difficulty } & \multicolumn{3}{|c|}{ Therapeutic outcome } \\
\hline & 1 & 2 & 3 & 4 & 5 & tim & success & failure \\
\hline A & 5 & 13 & 3 & 35 & 2 & $73.86 \pm 12.98$ & 53 & 5 \\
\hline B & 7 & 68 & 9 & 117 & 1 & $70.90 \pm 12.07$ & 195 & 7 \\
\hline$t / \chi^{2}$ & 2.72 & 2.66 & 0.05 & 0.11 & 3.45 & 1.62 & \multicolumn{2}{|c|}{2.72} \\
\hline$P$-value & 0.099 & 0.103 & 0.819 & 0.741 & 0.063 & 0.107 & \multicolumn{2}{|c|}{0.099} \\
\hline
\end{tabular}


Table III. Comparisons of postoperative clinical parameters between the two groups

\begin{tabular}{|c|c|c|c|c|c|c|c|c|c|c|c|}
\hline Groups & \multicolumn{2}{|c|}{$\begin{array}{l}\text { Duration of } \\
\text { continuous } \\
\text { ECG moni- } \\
\text { toring }[\mathrm{h}]\end{array}$} & $\begin{array}{l}\text { Use rate } \\
\text { of opioid } \\
\text { drugs }\end{array}$ & $\begin{array}{l}\text { Indwelling } \\
\text { time of } \\
\text { nasobiliary } \\
\text { drainage } \\
\text { tube [h] }\end{array}$ & $\begin{array}{l}\text { First out of } \\
\text { bed activity } \\
\text { time }[\mathrm{h}]\end{array}$ & \multicolumn{2}{|c|}{$\begin{array}{c}\text { First ex- } \\
\text { haust time } \\
{[\mathrm{h}]}\end{array}$} & $\begin{array}{l}\text { Total hos- } \\
\text { oitalization } \\
\text { time }\end{array}$ & \multicolumn{2}{|c|}{$\begin{array}{l}\text { Postopera- } \\
\text { tive hospi- } \\
\text { talization } \\
\text { time }\end{array}$} & $\begin{array}{l}\text { Hospital- } \\
\text { ization } \\
\text { expenses } \\
\text { RMB yuan) }\end{array}$ \\
\hline A & \multicolumn{2}{|c|}{$29.92 \pm 6.84$} & $0 / 58$ & $29.84 \pm 3.36$ & $16.63 \pm 8.61$ & \multicolumn{2}{|c|}{$26.38 \pm 8.24$} & $4.48 \pm 1.61$ & \multicolumn{2}{|c|}{$3.42 \pm 1.15$} & $\begin{array}{l}44899.11 \\
\pm 1105.08\end{array}$ \\
\hline B & \multicolumn{2}{|c|}{$20.84 \pm 7.32$} & $3 / 202$ & $30.65 \pm 4.38$ & $18.08 \pm 8.25$ & \multicolumn{2}{|c|}{$21.36 \pm 3.95$} & $4.29 \pm 1.13$ & \multicolumn{2}{|c|}{$3.35 \pm 1.45$} & $\begin{array}{l}44973.79 \\
\pm 1201.27\end{array}$ \\
\hline$t / \chi^{2}$ & \multicolumn{2}{|l|}{8.45} & - & 1.30 & 1.17 & \multicolumn{2}{|l|}{6.47} & 1.02 & \multicolumn{2}{|l|}{0.34} & 0.43 \\
\hline$P$-value & \multicolumn{2}{|l|}{$<0.01$} & 1.000 & 0.194 & 0.243 & \multicolumn{2}{|l|}{$<0.01$} & 0.309 & \multicolumn{2}{|l|}{0.736} & 0.671 \\
\hline \multirow[t]{2}{*}{ Groups } & \multicolumn{4}{|c|}{ Complications } & \multicolumn{2}{|c|}{ Complication severity } & \multicolumn{3}{|c|}{ Postoperative pain grade } & \multirow{2}{*}{$\begin{array}{l}\text { Read- } \\
\text { mission } \\
\text { rate } \\
\text { after } \\
\text { dis- } \\
\text { charge } \\
\text { of } 30 \mathrm{~d}\end{array}$} & \multirow{2}{*}{$\begin{array}{c}\text { Mortal- } \\
\text { ity }\end{array}$} \\
\hline & $\begin{array}{l}\text { Pancre- } \\
\text { atitis }\end{array}$ & $\begin{array}{l}\text { Bleed- } \\
\text { ing }\end{array}$ & $\begin{array}{l}\text { Perfo- } \\
\text { ration }\end{array}$ & $\begin{array}{l}\text { Infec- } \\
\text { tion }\end{array}$ & $\begin{array}{l}\text { Moder- } \\
\text { ate }\end{array}$ & Severe & Mild & $\begin{array}{l}\text { Moder- } \\
\text { ate }\end{array}$ & Severe & & \\
\hline A & 2 & 0 & 0 & 0 & 0 & 0 & 55 & 3 & 0 & 0 & 0 \\
\hline B & 7 & 1 & 0 & 2 & 2 & 0 & 187 & 12 & 3 & 0 & 0 \\
\hline$t / \chi^{2}$ & - & - & - & - & - & - & 0.36 & 0.05 & - & - & - \\
\hline$P$-value & 1.000 & 1.000 & - & 1.000 & 1.000 & - & 0.551 & 1.000 & 1.000 & - & - \\
\hline
\end{tabular}

cut length of the teat sphincter was determined according to the shape of the papillae and the size of the stones, and then the calculi were taken out with a net basket and air bag (Cook Medical, USA). If there were stones incarcerated in the duodenal ampulla of the lower part of the common bile duct, obvious enlargement and edema of the papillae and other difficult selective biliary cannulation (DSBC), the incarcerated stones should have been removed in advance by precutting the duodenal papilla or artifistulation, and then confirmed by ERCP examination. If the stone was too large, the distal end of net basket was connected to the winch to remove it by crushing the stone. If ERCP showed malignant biliary obstruction, a nasobiliary drainage tube or plastic stent was inserted into the liver or hepatic duct through the stricture obstruction under the guidance of the guide wire (Cook Medical, USA) to serve as preoperative biliary drainage. For a small number of patients with malignant obstructive jaundice in whom the preoperative evaluation indicated a low success rate of the resection and advanced age, permanent metallic biliary stents (Cook Medical, USA) were implanted without consideration of the surgical treatment.

\section{Treatment measures in the perioperative period of the ERAS group}

Unlike the traditional perioperative period, the treatment measures in the preoperative period of the ERAS group were as follows: 1) preoperative advice and education of the necessity of ERCP operation, routine process, risk, purpose and main content, discharge standard, pain and nutrition before and after the operation; 2) fasting more than $6 \mathrm{~h}$, oral administration of $10 \%$ glucose or xylitol $300 \mathrm{ml}$ (maximum $500 \mathrm{ml}$ ) within $2-3 \mathrm{~h}$ and then fluid deprivation for more than $2 \mathrm{~h}$; 3) no need for intestinal preparation; 4) exercising breathing with respiratory function trainer; 5) prophylactic intravenous drip of broad-spectrum antibiotic at 30 min before operation for high risk factors such as age, diabetes and immunodeficiency, according to antibiotic use requirements; 6) intravenous administration of $40 \mathrm{mg}$ of parecoxib sodium at $30 \mathrm{~min}$ before the operation for preemptive analgesia before anesthesia; 7) during the operation, controlled infusion of 4-6 $\mathrm{ml} /(\mathrm{kg} \mathrm{h})$ was used, and a nasobiliary drainage tube was inserted if necessary; 8 ) at 1-3 days after the operation, $40 \mathrm{mg}$ of parecoxib sodium was intra- 
venously given every $12 \mathrm{~h}$ (9 a.m. and 9 p.m.), and then the pain scoring was performed on day 4 . If the pain score was still higher than 4, intravenous administration of parecoxib sodium was continued until the pain was significantly relieved; 9) chewing gum promoted gastrointestinal peristalsis; 10 ) the oral proton pump inhibitor (PPI) esomeprazole (40 mg) was given once on the operation preparation day to relieve the stress reaction. After the operation, $40 \mathrm{mg}$ of esomeprazole in $100 \mathrm{ml}$ of physiological saline were intravenously given twice per day with fasting. After resuming eating, oral PPI (40 mg of parecoxib sodium) was continued. For Caprini scoring, if the score was 0-1 (low risk), early massage, early activity, and physical prevention were applied for prophylactic anticoagulation; if the score was 3 or more, medicinal prevention was needed. At 2-12 $\mathrm{h}$ before the operation, $0.4 \mathrm{ml}$ of $\mathrm{Cl}$ exane was subcutaneously injected once a day until discharge or 14 days after the operation. Patients with high risk needed combined mechanical measures (intermittent pneumatic compression pump or elastic stocking). Dexamethasone or 5-HT3 antagonists were used intraoperatively to prevent nausea and vomiting, and 5-HT3 antagonists were still given after the operation if necessary. At $24 \mathrm{~h}$ after the operation, if no abdominal distention, nausea and vomiting were observed, and if the volume of drainage was less than $10 \mathrm{ml}$, the nasobiliary drainage tube was removed. Eating was resumed gradually. After the operation, the patients took a semi-reclining position. Six hours later, the patients ambulated accompanied by the nursing staff, and the activity was recorded. Subsequently, the patients gradually began independent activity. The principle of target oriented intravenous infusion was to supplement sufficient calories, which were given according to the evaluation. The individual files and the follow-up list were set up when the patients were discharged. The patients were followed up for 7 days by call, considering pain, diet and other factors. Then the patients were continuously followed up for 30 days for their recovery and rehospitalization or death.

\section{Statistical analysis}

SPSS v24 statistical software was used for data processing. The measurement data were expressed as mean \pm standard deviation (SD) and compared using the $t$-test between groups, while the count data were expressed as percentage and compared using the $\chi^{2}$ test. $P<0.05$ was considered statistically significant.

\section{Results}

Comparisons of preoperative, intraoperative and postoperative clinical parameters

Before the operation, the incidences of cholangiocarcinoma, complications such as arrhythmia, coronary heart disease (CHD), hypertension, chronic obstructive pulmonary disease (COPD), liver dysfunction, nutritional screening score $\geq 3$ points, ASA degree III and Child-Pugh grade $A$ in group $A$ were significantly higher than those in group $B$, while the incidences of nausea and vomiting, abdominal pain, nutritional screening score $<3$ points and ASA degree I were significantly lower than those in group $B$ $(p<0.05)$. Intraoperatively, the incidence of juxta-ampullary duodenal diverticulum (JAD) in the internal or bottom papilla in group A with DSBC was significantly higher than that in group $B(p<0.05)$. After the operation, the duration of continuous ECG monitoring and first exhaust time in group A were significantly longer than those in group $B(p<0.05)$. The remaining parameters were not significantly different $(p>0.05$, Tables I-III).

\section{Success rate, failure rate and incidence of complications}

The success rate, failure rate and incidence of complications in group A were $91.38 \%$ (53/58), $8.62 \%(5 / 58)$ and $3.45 \%(2 / 58)$, respectively, while they were $96.53 \%(195 / 202), 3.47 \%$ (7/202) and $4.95 \%(10 / 202)$ respectively in group $A$, showing no significant differences between the two groups $(p>0.05)$. As for the other complications such as pancreatitis, bleeding, perforation and the incidence of infection, there were also no statistically significant differences ( $p>0.05$, Tables II and III).

\section{Discussion}

With the development of minimally invasive medical technology, the application of ERCP has now occupied an important position clinically. With the advantages of minimal invasiveness, effectiveness, short hospitalization and low incidence of complications, ERCP is the first choice for the treatment of many patients with biliary and pancreatic diseases, especially for elderly patients who are not suitable for an operation $[12,13]$. At the same time, the rational application of the ERAS concept can optimize 
the perioperative management of elderly patients, reduce trauma stress and complications, shorten the time of hospitalization and accelerate the recovery of the patients, with safety and effectiveness. The main aspects of ERAS include: the use of multiple modes for postoperative analgesia, early ambulation, early oral feeding, reducing or not using nasogastric tube decompression, shortening the time of preoperative fasting and fluid deprivation, avoiding excessive rehydration or deficiency of fluid in the operation, and encouraging the use of minimally invasive surgery [14].

Professor Kehlet believes that reducing surgical stress is the core principle of the ERAS concept, and is the basis for accelerating postoperative rehabilitation [15]. Preventive analgesia and multi-mode analgesia were used throughout the perioperative period in this study, and PPI was applied in the whole course, which reduced the perioperative stress and the risk of postoperative complications. After the operation, patients were encouraged to get out of bed early to prevent thrombosis and start an oral diet early to promote gastrointestinal function recovery. Such measures achieved good clinical outcomes, such as earlier activities and shorter length of stay, which were clearly beneficial for the patients. The operation's unique precision, minimal invasiveness and damage controlling advantages have become a gospel for patients with biliary and pancreatic diseases, especially for elderly patients with high operation risk.

In this study, the comparisons of the elderly group with the young and middle-aged group showed that the incidence of complications in the elderly was significantly higher than that in the young and middle-aged people. In addition, the high score of nutrition screening and the poor ASA score would increase the risk of anesthesia and operation, which should be paid sufficient attention to. Close inspection and diagnosis are necessary, especially in the perioperative period. The incidence of abdominal pain, nausea and vomiting in the elderly group before the operation was significantly lower than that in the young and middle-aged group, which was related to their insensitivity to some general discomfort symptoms. Owing to this, it could lead to delayed diagnosis. The incidence of complications reported in the literature is $5 \%$ to $10 \%[16,17]$. The ERAS program can reduce the inflammatory response after surgical trauma [18]. However, it was only $3.45 \%$ (2/58, pancreatitis) in the elderly ERAS group in this study, which was near to that in the middle and young group (4.95\%,
$10 / 202$ ), indicating that the age-related complications did not increase the incidence of complications. Thus, the applications of ERCP under the ERAS concept in the elderly was as safe and effective as in young and middle-aged patients [19-21].

It should be noted that the incidence of JAD cases in elderly patients was significantly higher than that in the young and middle-aged group. Most of the JAD cases are due to a congenital muscular defect of the duodenum, which is closely related to the occurrence of biliary and pancreatic diseases and obviously increases the difficulty of intubation, belonging to complex intubation. Such papillae are mostly accompanied by abnormal vascular distribution and inflammation, and are prone to complications after endoscopic sphincterotomy. However, in the current classifications of difficulty of operation, there are no evaluation criteria for JAD, papillary spasm, papilla stenosis, papilla lateral opening, Billroth II or Rouxen-Y gastrojejunostomy. It is suggested that the occurrence of DSBC in the operation should be added to the classifications of operation difficulty that originally only assess the operation mode. Due to the occurrence of DSBC, the corresponding difficulty level may need to be improved [22-25].

This group of ERCPs were performed by the same physician with more than 10 years of operational experience, which can avoid human factor errors due to different operators and enhance the rigor and comparability of the experiment; meanwhile, the experienced team of endoscopic physicians is also an important factor in ensuring the safety and efficacy of ERCP in elderly patients under the concept of ERAS.

\section{Conclusions}

The treatment effectiveness of ERCP under the ERAS concept in elderly patients with biliary and pancreatic diseases is as safe and effective as that used in young and middle-aged patients. ERCP under ERAS for patients with biliary and pancreatic disease can shorten the time of hospitalization, reduce postoperative pain and the economic burden, and benefit the patients. Thus, it has good clinical application value and promotion value.

\section{Acknowlegdments}

Fang Niu, Yu-Di Liu, Rong-Xia Chen contributed equally to this work. 


\section{Conflict of interest}

\section{The authors declare no conflict of interest.}

\section{References}

1. Wu DP. Value of endoscopic retrograde cholangiopancreatography in diagnosis and treatment of biliary and pancreatic disease in elderly. China J Endosc 2015; 21: 999-1002.

2. Han SJ, Lee TH, Kang BI, et al. Efficacy and safety of therapeutic endoscopic retrograde cholangiopancreatography in the elderly over 80 years. Dig Dis Sci 2016; 61: 2094-101.

3. Nelson G, Altman AD, Nick A, et al. Guidelines for postoperative care in gynecologic/oncology surgery: Enhanced Recovery After Surgery $\left(\right.$ ERAS $\left.^{\oplus}\right)$ Society recommendations--Part II. Gynecol Oncol 2016; 140: 323-32.

4. Specht K, Kjaersgaard-Andersen P, Kehlet H, et al. High patient satisfaction in 445 patients who underwent fast-track hip or knee replacement. Acta Orthop 2015; 86: 702-7.

5. Kehlet H. Multimodal approach to control postoperative pathophysiology and rehabilitation. Br J Anaesth 1997; 78: 606-17.

6. Findlay JM, Gillies RS, Millo J, et al. Enhanced recovery for esophagectomy: a systematic review and evidence-based guidelines. Ann Surg 2014; 259: 413-31.

7. Pędziwiatr M, Pisarska M, Kisielewski M, et al. ERAS protocol in laparoscopic surgery for colonic versus rectal carcinoma: are there differences in short-term outcomes. Med Oncol 2016; 33: 56.

8. Nelson G, Altman AD, Nick A, et al. Guidelines for pre- and intra-operative care in gynecologic/oncology surgery: Enhanced Recovery After Surgery (ERAS ${ }^{\circledR}$ ) Society recommendations--Part I. Gynecol Oncol 2016; 140: 313-22.

9. Tohda G, Ohtani M, Dochin M. Efficacy and safety of emergency endoscopic retrograde cholangiopancreatography for acute cholangitis in the elderly. World J Gastroenterol 2016; 22: 8382-8.

10. Zhao YP, Xiong LZ. Consensuson ERAS and guidelines for pathway management in China (2018). Chin J Anesthesiol 2018; 38: 8-13.

11. Cotton PB, Lehman G, Vennes J, et al. Endoscopic sphincterotomy complications and their management: an attempt at consensus. Gastrointest Endosc 1991; 37: 383-93.

12. Hughes MJ, McNally S, Wigmore SJ. Enhanced recovery following liver surgery: a systematic review and meta-analysis. HPB (Oxford) 2014; 16: 699-706.

13. Stone AB, Grant MC, Pio Roda C, et al. Implementation costs of an enhanced recovery after surgery program in the United States: a financial model and sensitivity analysis based on experiences at a Quaternary Academic Medical Center. J Am Coll Surg 2016; 222: 219-25.

14. Li JS, Jiang ZW. Clinical significance of enhanced recovery after surgery is not only to shorten the duration of hospital stay. Chin J Dig Surg 2015; 14: 22-4.

15. Kehlet H. Fast-track hip and knee arthroplasty. Lancet 2013; 381: 1600-2.

16. Rustagi T, Jamidar PA. Endoscopic retrograde cholangiopancreatography-related adverse events: general overview. Gastrointest Endosc Clin N Am 2015; 25: 97-106.
17. Razavi F, Gross S, Katz S. Endoscopy in the elderly: risks, benefits, and yield of common endoscopic procedures. Clin Geriatr Med 2014; 30: 133-47.

18. Wierdak M, Pisarska M, Kuśnierz-Cabala B, et al. Use of inflammatory markers in the early detection of infectious complications after laparoscopic colorectal cancer surgery with the ERAS protocol. Videosurgery Miniinv 2018; 13: 315-25.

19. Behlül B, Ayfer S, Sezgin V, et al. Safety of endoscopic retrograde cholangiopancreatography in patients 80 years of age and older. Prz Gastroenterol 2014; 9: 227-31.

20. Garcia CJ, Lopez OA, Islam S, et al. Endoscopic retrograde cholangiopancreatography in the elderly. Am J Med Sci 2016; 351: 84-90.

21. Ukkonen M, Siiki A, Antila A, et al. Safety and efficacy of acute endoscopic retrograde cholangiopancreatography in the elderly. Dig Dis Sci 2016; 61: 3302-8.

22. Mok SRS, Ho HC, Shah P, et al. Lactated Ringer's solution in combination with rectal indomethacin for prevention of post-ERCP pancreatitis and readmission: a prospective randomized, double-blinded, placebo-controlled trial. Gastrointest Endosc 2017; 85: 1005-13.

23. Finkelmeier F, Tal A, Ajouaou M, et al. ERCP in elderly patients: increased risk of sedation adverse events but low frequency of post-ERCP pancreatitis. Gastrointest Endosc 2015; 82: 1051-9.

24. Ozogul B, Ozturk G, Kisaoglu A, et al. The clinical importance of different localizations of the papilla associated with juxtapapillary duodenal diverticula. Can J Surg 2014; 57: 337-41.

25. Han M, Sun CY, Qin JG, et al. Retrospective analysis of 3881 cases of endoscopic retrograde cholangiopancreatography. China J Endosc 2013; 19: 1090-4.

Received: 7.12.2018, accepted: 23.01.2019. 